Comunicação: Sem hipérboles ou eufemismos: o processo penal como garantia de direitos fundamentais

\title{
SEM HIPÉRBOLES OU EUFEMISMOS: O PROCESSO PENAL COMO GARANTIA DE DIREITOS FUNDAMENTAIS
}

\author{
WITHOUT HYPERBOLES OR EUPHEMISMS: THE CRIMINAL PROCESS AS A GUARANTEE OF \\ FUNDAMENTAL RIGHTS
}

RESUMO

Este artigo se propõe a discorrer a respeito da relação entre o princípio da publicidade dentro do Processo Penal, a presunção de inocência e a exposição midiática da pessoa acusada; todos esses elementos sob a ótica garantista do Processo, em consonância com os ditames do Estado Democrático de Direito e a dignidade da pessoa humana. Para tal, pretende-se a seguinte subdivisão do artigo. Na primeira seção, encontra-se breve explanação do Processo Penal Acusatório, do papel dos diversos personagens que dele participam, e seu compromisso para com a pessoa acusada, inclusive com a preservação de sua imagem. Já na segunda seção, o artigo adentra nos meandros do princípio da publicidade, expondo sua fundamental importância à democracia, inclusive do ponto de vista histórico, e as consequências danosas de sua deturpada utilização. Na terceira seção ventila-se a ideia de presunção de inocência, fundamento iluminista e marco do Estado civilizatório, que traz em seu conceito o estado natural de inocência. Por fim, o limiar do princípio da publicidade e o da presunção de inocência caminham ao encontro do que a Constituição de 1988 idealizou por Estado Democrático de Direito; em razão disso, aqueles que operam dentro do processo penal possuem a absoluta necessidade de observância e zelo por esses dois princípios. Não menor cuidado deve-se exigir da impressa e de outros veículos de comunicação que, assim como operadores do direito, encontram sua função disposta no texto constitucional, oriunda do direito à informação.

PALAVRAS-CHAVE: Processo criminal. Direito fundamental. Publicidade. Estado democrático de direito.

\section{ABSTRACT}

The article proposes to discourse about the relationship between the principle of publicity within the Criminal Procedure, the presumption of innocence and the media exposure of the accused person. All of these elements from the perspective of those who fight for the maintenance of the accused person's fundamental rights, in line with the dictates of the Democratic Rule of Law and the dignity of the human person. To this end, the article is subdivided as follows. In the first session, there is a brief explanation of the Accusatory Criminal Procedure, the role of the various characters who participate in it, and their commitment to the accused person, including the preservation of their image. In the second session, the article delves into the intricacies of the principle of advertising, exposing its fundamental importance to democracy, including from the historical point of view, and the harmful consequences of its misuse use. Furthermore, in the third session it is placed under debate the idea of the presumption of innocence: an Illuminist foundation and a milestone of the civilizing state, which brings in its concept of the natural state of innocence. Lastly, the threshold of the principle of publicity and the presumption of innocence are in line with what the 1988 Constitution idealized as a Democratic State of Law, thereat, those who operate within the criminal process, have the absolute need for observance and zeal of these two principles. No less care should be demanded from the press and other means of

\footnotetext{
*Mestranda em Direito pela PUC-SP. E-mail: marinayfrederico@bol.com.br.
} 
communication that, as well as the operators of the law, find their function laid out in the constitutional text, what comes from the right to information.

KEY WORDS: Criminal process. Fundamental rights. Publicity. Democratic State of Law.

\section{PROCESSO PENAL NO ESTADO DEMOCRÁTICO DE DIREITO}

O processo Penal, como deve ser interpretado em um Estado Democrático de Direito, possui todas as bases dentro dos ditames constitucionais, em total consonância com outras garantias, como, por exemplo, o direito à informação.

Assim é que se pretende analisar brevemente a relação entre o processo penal (que abordaremos quanto à sua estrutura e finalidade dentro do Estado Democrático de Direito) e a sociedade de informação com base, principalmente, no quesito do direito à informação.

Desse modo, para contextualizar o processo penal dentro de uma sociedade democrática, faz-se mister entendê-lo como instrumento que zela pela dignidade da pessoa humana, principalmente a do cidadão acusado. Para discorrermos a respeito, consultaremos, dentre outras, a obra Acesso à justiça penal e estado democrático de direito, do professor Marco Antônio Marques da Silva (2001).

De acordo com o autor, ao contrário do que se espera em um estado liberal - que possui como premissa a abstenção máxima do Estado e, por conseguinte, a simples disposição de direitos fundamentais, sem ações positivas para que garantias possam ser gozadas por todos —, o Estado Democrático de Direito exige que haja mecanismos que possibilitem a efetivação dos direitos já dispostos a todos os cidadãos, com equidade. Isso se viabiliza por meio do processo legal. Veja-se:

\footnotetext{
Nesse contexto, o processo é a ponte por excelência entre o cidadão e o poder jurisdicional; ainda que seja mostrado como um instrumento técnico aparentemente neutro, [...] se modifica, como todo o resto do direito, de acordo com as modificações políticas e até mesmo econômicas que ocorrem na sociedade. (SILVA, 2001, p. 76).
}

Entretanto, o processo serviu, por séculos, na sociedade, como um instrumento de imposição do poder constituído, uma vez que o povo, em um regime autoritário, possui poucos ou nenhum direito político-jurídico.

Seguidamente, com o advento das revoluções francesa e inglesa, que garantiram aos cidadãos direitos fundamentais frente ao Estado, o processo tornou-se o conjunto de 
Comunicação: Sem hipérboles ou eufemismos: o processo penal como garantia de direitos fundamentais

procedimentos para alcançar e proteger esses direitos. Torna-se, desse modo, nas palavras de Silva (2001), garantia constitucional ao cidadão.

Destarte, encontra-se nesse momento histórico a mudança do processo penal inquisitório para o processo penal com raízes acusatórias, de modo que a principal característica desse "novo" modelo manifesta-se na divisão de funções entre o juiz e o promotor, como bem expressa Luigi Ferrajoli (2002, p. 575), na obra Derecho y razón ${ }^{l}$. de

Voltando os olhos para o direito brasileiro, embora o País seja legislado sob a égide de um Estado Democrático de Direito, não se pode olvidar e, muito menos ignorar, que o Código de Processo Penal (escrito em pleno regime ditatorial do Estado Novo) traga, em alguns de seus dispositivos ${ }^{2}$, traços do processo inquisitivo, que revelam a capacidade de intervenção e atuação do magistrado muito mais ampla do que seria permitido em um processo acusatório. Em razão disso, Aury Lopes Jr (2015) afirma ser inquisitivo o nosso sistema processual, visto que o ordenamento jurídico faculta ao juiz não apenas investigar dentro do processo, mas, além disso, gerir provas.

Todavia, a presente pesquisa, no que concerne à denominação de nosso sistema, crê na imprescindibilidade de entendermos o processo penal brasileiro como acusatório, visto que a Constituição Federal discorre a respeito das garantias fundamentais e, como a Carta se apresenta em nosso sistema como Lei Maior, todas as normas infraconstitucionais devem obedecer aos seus ditames (e guiar-se por seus princípios). O contrário do que se encontra escorreito na Carta Cidadã deve ser visto como inconstitucional e, por conseguinte, nulo em sua aplicação. Assim é que para Lopes Jr (2015, p. 49),

Precisamos compreender que a Constituição de 1988 define um processo penal acusatório, fundado no contraditório, na ampla defesa, na imparcialidade do juiz e nas demais regras do devido processo penal. Diante dos inúmeros traços inquisitórios do processo penal brasileiro, é necessário fazer uma "filtragem constitucional" dos dispositivos incompatíveis com o princípio acusatório (como o art. 156, 385 etc.), pois são "substancialmente inconstitucionais". Assumido o problema estrutural do CPP, a luta passa a ser pela acoplagem constitucional e pela filtragem constitucional, expurgando de eficácia todos aqueles dispositivos que, alinhados ao núcleo inquisitório, são incompatíveis com a matriz constitucional acusatória.

\footnotetext{
${ }^{1}[\ldots]$ al sistema acusatório le corresponde um juez espectador dedicado sobre todo a ala objetiva e imparcial valoración de los hechos y, por ello, más sábio que experto, el rito inquisitivo exige sin embargos un juez actor, representante del interes, punitivo y, por ello, leguleyo, versado em el procedimento y dotado de capacidad de investigación.

${ }^{2}$ Veja Aury Lopes Junior (2015, p. 48).
}

Sapere aude - Belo Horizonte, v. 11 - n. 22, p. 589-601, Jul./Dez. 2020 - ISSN: 2177-6342 
O presente posicionamento estende-se, inclusive, ao inquérito policial, uma vez que se trata de um instituto regrado pelas normas do Código de Processo Penal, o qual, por sua vez, encontra-se submisso aos ditames da Carta Maior.

Em razão disso, por se afigurar apropriado em um Estado Democrático que o processo seja gerido com garantias constitucionais e que a prestação jurisdicional advenha "de um magistrado independente, política, econômica e moralmente" (MARQUES, 2001, p. 08), entende-se pouco democrática a prática de juízes agindo às avessas de princípios fundamentais, concedendo entrevistas à imprensa atestando suas posições políticas, ideológicas e, até mesmo, partidárias. Além do que, e mais gravoso ainda, juízes atestarem publicamente suas posições dentro do processo que estão julgando, mostrando-se intencionais (o que corrompe por completo, o princípio constitucional da imparcialidade da jurisdição).

Note-se que em hipótese alguma se defende aqui censurar o acesso da imprensa aos autos, uma vez que tal direito faz-se inerente ao sistema processual democrático, guiado pelo princípio da publicidade (tema da segunda seção deste texto), mas não é admissível deturpá-lo em seu nevrálgico compromisso com a democracia. O princípio da publicidade é fruto da também constitucional liberdade de comunicação, que garante à sociedade a livre manifestação de pensamento, informação e informação jornalística.

Discorreremos aqui a respeito da liberdade de informação, um direito distinto do "direito à informação", que por sua vez encontra-se no rol de direitos coletivos. Para explanarmos sobre o assunto, será de fundamental importância a obra Curso de direito constitucional positivo, de José Afonso da Silva (2014).

Esse princípio constitucional se mostra extremamente caro à democracia nacional, pois por muitos anos as informações oriundas da imprensa foram sufocadas pela censura que, por meio de um crivo político, determinava informações passíveis ou não de serem divulgadas.

Assim, no Brasil pós-redemocratização, faz-se crucial esclarecer que o direito, a duras penas conquistado, compreende liberdade de informar e de ser informado, ser bem informado. Ele, no dizer de Albino Greco (apud SILVA, 2014),

[...] coincide com a liberdade de manifestação do pensamento pela palavra, por escrito ou por qualquer outro meio de difusão; [...] indica o interesse sempre crescente da coletividade para que tanto os indivíduos como a comunidade estejam informados para o exercício consciente das liberdades públicas. 
Comunicação: Sem hipérboles ou eufemismos: o processo penal como garantia de direitos fundamentais

Vejamos que o direito consiste em transmitir informações precisas e sem pressupostos morais, exceto em se tratando de artigo de opinião. Em se tratando de noticiar fatos criminosos, jamais se poderá afirmar ser determinado cidadão culpado, antes da sentença condenatória. Em razão disso, muito causa espanto e enorme prejuízo a uma sociedade democrática a "liberdade" que alguns "jornais informativos" possuem de, logo após o fato supostamente criminoso (muitas vezes sequer denúncia formal existe), expor a imagem de determinado suspeito, tachando-o de criminoso, sendo que, à luz da Constituição Federal e do Código de Processo Penal democrático, até aquele momento, sequer réu aquele cidadão se tornou. Note-se que a liberdade de informar implica extremo zelo com a responsabilidade de passar à população os fatos de modo objetivo, sem hipérboles ou eufemismos.

E já que estamos tratando de informações transmitidas por meio da imprensa, devemos voltar os olhos para a liberdade de informação jornalística, ainda nos apoiando nos conhecimentos de José Afonso da Silva (2014).

Posto isso, trazendo essa crítica à exacerbada exposição dos processos penais, pode-se afirmar que também o Judiciário muitas vezes incorre em equívoco democrático ao julgar processos conforme o vetor do clamor popular, em vez de subordinar-se única e exclusivamente aos ditames do devido processo legal.

Cabe ressaltar que a transmissão ao vivo de julgamentos, por vezes envolvendo pessoas públicas e interesses políticos, tem se manifestado, em não raros momentos, mais penoso do que benéfico ao Estado de Direito. Assim se entende, pois, que o elemento básico do sistema acusatório é a imparcialidade da jurisdição, aqui mencionada à exaustão.

Todavia, juízes, desembargadores e ministros veem-se expostos a toda a população ignorante, no literal sentido do termo, a respeito de garantias fundamentais do acusado, e insuflada também por uma mídia persecutória - afinal é mais rentável vender um fato de forma sensacionalista e trágica. Assim, no momento de noticiar a possível futura condenação, vende-se a "culpa" do acusado antes mesmo da sentença condenatória; clama-se ainda para que o acusado seja apenado do modo mais gravoso possível. De tal maneira e no rastro deixado por esse ambiente, muitas vezes para não macular a própria imagem perante a população, outras tantas vezes para transmitir imagem heroica - o que foge por completo da função de qualquer operador do direito - o julgador acaba proferindo sua sentença ou seu voto à deriva do processo penal constitucional, aparentemente cedendo ao que pede um certo "senso de justiça" da população. 
Dessa forma, se em todo e qualquer processo essa exposição manifesta-se danosa, naqueles que correm sob o rito do tribunal do júri, tal violação interfere mais enfaticamente no trâmite processual em si. Isso ocorre, pois o cidadão acusado será julgado por pessoas leigas, muitas vezes desprovidas de formação adequada para analisar criticamente as informações que lhes chegam pelos meios de comunicação. Assim, jurados votam pela condenação, levados, muito mais, pelas prévias informações (e pré-julgamentos) que possuíam do caso do que pelos fatos que lhes foram apresentados em plenário.

Tratando um pouco desse instituto e retomando sua historicidade, esse rito processual, desde a primeira vez que positivado no texto legal, carrega em si o princípio da publicidade. Nos crimes com pena superior a seis meses de prisão, o julgamento passou a ser pelo júri e era público e oral. No Capítulo III, foi normatizado o procedimento de Jury de Accusação, e de Sentença, e Peculiaridades aos Casos de Abuso da Liberdade de Exprimir os Pensamentos.

art.228. As sessões dos Jurados serão todas públicas, excepto quando houver votação; mas ninguém assistirá a ellas com armas, ainda que não seja das defezas, de qualquer natureza que forem, sob pena de ser preso, como em flagrante, e punidos com as penas impostas aos que usam de armas defezas. (BRASIL, 1832).

Por fim, faz-se mister reafirmar que, dentro de uma sociedade democrática e em um Estado de Direito, o processo penal deve ser instrumento das garantias fundamentais ao cidadão. Por isso deve ser pautado em ditames constitucionais, dentre eles o princípio da publicidade, levado a cabo juntamente com o respeito à presunção de inocência.

\section{A PUBLICIDADE DEMOCRÁTICA NO PROCESSO PENAL CONSTITUCIONAL}

Cabe agora abordar o princípio da publicidade - como já mencionado, oriunda do direito à informação - e defrontá-lo com os limites impostos por outros direitos, como, por exemplo, a dignidade da pessoa humana. Além disso, será debatido o uso que a mídia faz desse fundamento (publicidade) em detrimento de outras garantias individuais.

Destarte, antes de adentrarmos no cerne da questão, faz-se mister discorrer brevemente a respeito da historicidade do princípio da publicidade.

Sob a influência de ideais iluministas, a carta constitucional do império, outorgada em 1824, trazia em vernáculo, direitos civis e políticos que até hoje vigoram. Dentre eles, podemse ressaltar diversas normas de cunho processual, como, por exemplo, prisão em flagrante, 
Comunicação: Sem hipérboles ou eufemismos: o processo penal como garantia de direitos fundamentais

nota de culpa, fiança e independência do juiz. Vemos que se tratava de uma reação à opressão monárquica da metrópole que asfixiou o Brasil em todo o período colonial, por meio das Ordenações Filipinas. Além dessas garantias, mencionava-se o princípio da publicidade: "Art. 159. Nas causas crimes a inquisição das testemunhas e todos os mais atos do processo, depois da pronúncia, serão públicos desde já.” (CABRERA, 2005, p. 67).

Percebe-se no mencionado dispositivo, a explícita aderência ao direito fundamental da informação a todo e qualquer cidadão. Entretanto essa realidade não perdurou até a Constituição Republicana, outorgada em 1881. Nesta carta, muito embora outras garantias fundamentais processuais se mantivessem intactas, o princípio da publicidade não encontrou espaço no texto legal. Além do que não se pode olvidar que a Constituição Republicana concedeu a cada Estado a faculdade de legislar a respeito das esferas processuais - civil e criminal.

Gozando da omissão constitucional a respeito do princípio da publicidade, alguns códigos legitimaram atos do processo secretos, como, por exemplo, a formação da culpa secreta, além do sigilo na fase investigatória.

Seguidamente, as cartas constitucionais que vigeram após a proclamação da "República dos Estados Unidos do Brasil" não dispuseram expressamente a respeito do princípio da publicidade. Já a Constituição de 1937, fazendo jus ao regime ditatorial à qual pertencia, restringiu ainda mais o direito à informação.

A seguir, após a Constituição de 1946, a Constituição do Brasil de 1967, emendada em 1969, dispunha: "Art. 153, \$36. A especificação dos direitos e garantias expressos nessa Constituição não exclui outros direitos e garantias decorrentes do regime e dos princípios que ela adota." (CABRERA, 2005, p. 67).

Sendo assim, questiona-se: quais garantias e direitos decorrem de um regime ditatorial, tal e qual a ditadura civil-militar de 1964? Soa curioso o texto emanado de um tal regime autoritário e antidemocrático afirmar que esse mesmo sistema assegurará direitos fundamentais ao cidadão.

Pode-se aferir, com isso, a imprescindibilidade do princípio da publicidade estar explicitamente disposto no texto constitucional, para que não haja a menor possibilidade de interpretação em contrário, caminhando, dessa forma, ao encontro da construção de um Estado Social e Democrático de Direito.

Nesse sentido entendeu a Constituinte de 1988, pois, de modo explícito e indubitável, fez-se presente o princípio da publicidade na Carta Cidadã vigente até os dias atuais. Por força 
do art. $5^{\circ}$, inciso, LX, "a lei só poderá restringir a publicidade dos atos processuais quando a defesa da intimidade ou o interesse público exigirem". Ainda no mesmo diploma, Art. 93, inciso IX: "todos os julgamentos dos órgãos do Poder Judiciário serão públicos, e fundamentadas todas as decisões, sob pena de nulidade, podendo a lei, se o interesse público o exigir, limitar a presença, em determinados atos, às próprias partes e seus advogados, ou somente a estes."

Dessa forma, manifesta-se inserido também o princípio da publicidade no processo penal, objeto de estudo do presente artigo. Pode-se afirmar, com isso, que se trata de uma garantia fundamental a todos os cidadãos (não apenas aos que se encontram como parte no processo) de que os atos correntes nos autos poderão ser devidamente "controlados", "fiscalizados" e supervisionados pela sociedade.

Assim, a publicidade no processo penal vem em contraponto aos atos secretos inerentes ao processo inquisitivo, trazendo aos olhos de todos, como, por que, e de que modo um cidadão está sendo acusado pelo Estado. O rito disposto na legislação está sendo cumprido ipsis litteris? As garantias constitucionais do acusado estão sendo respeitadas, ou há alguma violação? Todos esses pontos podem ser postos à prova por qualquer ente da sociedade, graças ao princípio da publicidade.

Esse princípio pode ser "dividido" em duas formas: absoluto e relativo. A publicidade absoluta ocorre nos processos (ou atos do processo) a que todo e qualquer cidadão, independentemente de procuração, pode ter acesso; ilustrando: o plenário do júri. Já a publicidade relativa é acessível apenas às partes do processo e seus procuradores. No caso do processo penal, os atos processuais, em regra, são de ordem pública, exceto nos casos em que envolvidos são menores de dezoito anos, ou se a intimidade da parte é tema do processo. Além disso, em prol da segurança de testemunhas, não raras vezes, seus nomes são protegidos.

Outrossim, o acesso às informações inerentes ao processo penal, por força do princípio da publicidade, também pode/deve ser realizado, pelos meios de comunicação, como afirma o processualista James Goldschmidt (2002, p. 100):

Hodiernamente, considerando-se que esse controle se realize nem tanto pela assistência do grande público às sessões quanto pelas reportagens dos debates nos jornais, o pedido que se faz, às vezes, de proibir a imprensa de acompanhar os processos ainda não conclusos por sentença firme equivale a uma redução da publicidade. Além do mais, existe uma publicidade relativa, em forma de 
"publicidade para as partes", ou seja, a acessibilidade ao ato judicial concedida às partes.

Posto isso, percebe-se a imprescindibilidade de os meios de comunicação gozarem do acesso ao que ocorre nos processos judiciais. Entretanto, esse princípio encontra seus limites no que tange à exposição da intimidade ou da imagem de pessoas indevidamente expostas, como disposto no art. 5, inciso XL da Lei Maior: "a lei só poderá restringir a publicidade dos atos processuais quando a defesa da intimidade ou o interesse social o exigirem”.

Além desses direitos, menciona-se a garantia da honra e da imagem, que muito bem conceituadas foram por José Afonso da Silva em sua obra Curso de Direito Constitucional Positivo (2014, p. 211):

\begin{abstract}
A honra é um conjunto de qualidades que caracterizam a dignidade da pessoa, o respeito dos cidadãos, o bom nome, a reputação. É direito fundamental da pessoa resguardar essas qualidades, A pessoa tem o direito de preservar a própria dignidade - adverte Adriano de Cupis - mesmo fictícia, até contra ataques da verdade, pois aquilo que é contrário à dignidade da pessoa humana deve permanecer um segredo dela própria. Esse segredo entra no campo da privacidade, da vida privada, e é aqui onde o direito à honra se cruza com o direito à privacidade.
\end{abstract}

Ainda, citando o mesmo constitucionalista (2014, p. 211):

\begin{abstract}
A inviolabilidade da imagem da pessoa consiste na tutela do aspecto físico, como é perceptível visualmente, segundo Adriano Cupos que acrescenta: "Essa reserva pessoal, no que tange ao aspecto físico — que, de resto, reflete também personalidade moral do indivíduo — satisfaz uma exigência espiritual de isolamento, uma necessidade eminentemente moral”.
\end{abstract}

Diante dessas ponderações trazidas pelo estudo do Direito Constitucional, manifestase o seguinte ponto: em prol do princípio da publicidade no processo penal, é legitimo que os meios de comunicação maculem a honra de pessoas, que muitas vezes sequer foram condenadas em primeira instância? Faz-se democrático que violem a imagem daqueles que sequer réus são considerados?

Não raras vezes presenciamos os veículos de comunicação violando os dois direitos em questão, expondo detalhes desabonadores de réus que, novamente, sequer foram julgados.

À vista disso, ser alheio ao princípio da publicidade é utilizá-lo para corromper os preceitos da dignidade da pessoa humana. Pois este é fundamento para um Estado Democrático de Direito, modelo este que existe em função da preservação de direitos individuais e coletivos. 
Concluindo, não se manifesta compatível com um Estado Democrático de Direito que a dignidade de um cidadão seja preterida em prol da mercantilização de um fato supostamente criminoso. Por isso, reafirma-se que a midiatização de um processo penal é a distorção do princípio da publicidade. Enquanto a espetacularização caminha de encontro aos valores republicanos, preocupando-se pura e simplesmente com o lucro dos meios de comunicação; o princípio da publicidade (quando respeitado e respeitador de outras garantias) visa à construção e ao fortalecimento da democracia.

\section{PRESUNÇÃO DE INOCÊNCIA COMO PRINCÍPIO, O ESTEIO DA DEMOCRACIA}

Tratemos do princípio basilar do processo penal democrático, a presunção de inocência. O vocábulo "presunção" traz sua origem no latim "presumptum", que significa conjuntura ou ideia antecipada. Logo, podemos dizer que a ideia antecipada, ao se tratar de investigação criminal, é a de que o estado natural do homem é a inocência. Esse ponto, se analisarmos em um contexto de Estado e evolução histórica de direitos, deve ser entendido como uma garantia política, não apenas processual.

Desse modo, muito embora a presunção de inocência não esteja disposta ipsis litteris na Constituição Federal, em hipótese alguma pode-se afirmar que não se trata de uma garantia constitucional, visto que é inerente à dignidade da pessoa humana, prevista no art. 1, inciso III da Carta Cidadã. É uma condição inerente à personalidade humana, independente de todo e qualquer fator externo.

A presunção de inocência, aos olhos da evolução constitucional do processo penal, transforma o acusado não em mero objeto da persecução penal, mas, sim, em agente de direitos e garantias que têm como fundamento essa presunção, transformando o processo penal em um conjunto de regras cuja finalidade seja na preservação da garantia da presunção de inocência. Pode-se afirmar, a partir disso, que qualquer desrespeito à norma processual penal é uma violação ao princípio em questão.

Mas, não se pode colocar esse princípio como algo apenas abstrato, tornando imprescindível sua aplicabilidade e imprescindibilidade, que, por sua vez, ocorre por meio do princípio do contraditório, do qual a presunção de inocência manifesta-se corolário. Este, por sua vez, necessita do princípio da publicidade para ser efetivo. Percebe-se que a união dessas três garantias constitucionais, quando respeitadas a cabo, caminha ao encontro da estrutura do Estado Democrático de Direito. Todavia, a partir do momento em que o princípio da 
Comunicação: Sem hipérboles ou eufemismos: o processo penal como garantia de direitos fundamentais

publicidade é desviado de seus fundamentos para suprimir a presunção de inocência, passamos a nos deparar com ranços de atos pouco democráticos.

Outrossim, o princípio da presunção de inocência, para Carrara e a para a Escola Clássica, toma por base toda a estrutura do processo penal democrático, uma vez que

[...] o procedimento criminal (direito processual penal) teria como ponto de partida o pressuposto de ter diante de si um inocente. Desse modo, o direito penal substantivo servira essencialmente para a defesa dos direitos de um culpável enquanto que o direto processual penal serviria para a defesa e proteção do inocente. (MARQUES, 2001, p. 29).

Pode-se afirmar, desse modo, que o princípio da presunção de inocência é um dever de tratamento interno e externo ao processo. Do ponto de vista interno, é inerente a esse tratamento que o acusado possua absoluta ciência das imputações que recaem sobre ele para, dentro do prazo legal, exercer plenamente o direito ao contraditório e, por conseguinte, a ampla defesa. Para tal, como explanado, faz-se mister o princípio da publicidade.

\section{CONSIDERAÇÕES FINAIS}

Adentrando num ponto nevrálgico do tema, o princípio da presunção de inocência manifesta-se como um dever de tratamento interno e externo aos autos. $\mathrm{O}$ tratamento interno impõe aos atores do processo dirigirem-se ao acusado como inocente em todos os atos processuais. Inclusive, manifesta-se muito polêmico o uso, muitas vezes excessivo, das medidas cautelares, justamente porque se vê a mácula à garantia fundamental, em tela referida.

Já externamente, a presunção de inocência vincula toda a sociedade a tratar o cidadão acusado como inocente, principalmente obrigando os meios de comunicação a respeitarem esse dever de tratamento. Entretanto, pode-se aferir diversos exemplos de distorções do princípio da publicidade pelos meios de comunicação, ao divulgarem informações imprecisas a respeito de determinados processos, ou até mesmo inquéritos (LOPES JUNIOR, 2015) que, por sua vez, possuem um caráter absolutamente sigiloso. Além disso, não raras vezes, condenam socialmente o acusado, antes mesmo da sentença penal condenatória, o que se manifesta aviltante à democracia, como já explanado. Assim, nas palavras de Aury Lopes Jr (2015, p. 96): 


\begin{abstract}
Externamente ao processo, a presunção de inocência exige uma proteção contra a publicidade abusiva e a estigmatização (precoce) do réu. Significa dizer que a presunção de inocência (e também as garantias constitucionais da imagem e dignidade e privacidade) deve ser utilizada como verdadeiros limites democráticos à abusiva exploração midiática em torno do fato criminoso e do próprio processo judicial. O bizarro espetáculo montado pelo julgamento midiático deve ser coibido pela eficácia da presunção de inocência.
\end{abstract}

Destarte, aos olhos do processo penal constitucional, o principal zelador do princípio da presunção de inocência deve ser o presidente do processo, isto é, o magistrado.

Bem se vê que o princípio da publicidade encontra sua maior guarida no plenário do Tribunal do Júri, onde todo e qualquer cidadão poderá assistir à inquirição das testemunhas, as declarações da vítima e do réu, os debates orais e, ao final, a sentença. Encontra exceção a essa regra, obedecendo ao disposto no art. $5^{\circ}$ inciso XIV, a ressalva em prol da segurança ou a intimidade dos depoentes, ordenando o juiz, dessa forma, que os presentes se retirem, restando apenas o depoente, jurados, serventuários da justiça, promotor e advogado.

Concluindo, não se nega em um Estado Democrático de Direito, a imprescindibilidade do princípio da publicidade dentro do processo penal e, por conseguinte, a fiscalização desses processos pelos meios de comunicação. Todavia, a partir do momento em que se manifesta a usurpação e o desrespeito à presunção de inocência como dever de tratamento externo aos autos, a veiculação de notícias deve ser coibida de plano, mesmo em contraponto ao argumento, muitas vezes falacioso, de que a notícia (mesmo que exacerbada) possui uma finalidade social.

\title{
REFERÊNCIAS
}

BRASIL. Código de Processo Penal, 1832. Disponível em:

http://www.planalto.gov.br/ccivil_03/leis/LIM/LIM-29-11-1832.htm. Acesso em: 01 nov.2020.

CABRERA, Fernando José. O princípio da publicidade no direito processual penal:

direito das relações sociais. Dissertação de mestrado, orientada por Prof. Títular Hermínio Alberto Marques Porto, apresentada na PUC-SP, em Direito das Relações Sociais. São Paulo: PUC. 2005.

FERRAJOLI, Luigi. Derecho y razón. 3. ed. São Paulo: Revista dos Tribunais, 2002.

GOLDSCHIMIDT, James Paul. Princípios gerais do processo penal: conferências proferidas na Universidade de Madrid. Belo Horizonte: Líder, 2002.

LOPES JÚNIOR, Aury. Direito Processual Penal. 12. ed. São Paulo: Saraiva, 2015. 
Comunicação: Sem hipérboles ou eufemismos: o processo penal como garantia de direitos fundamentais

SILVA, José Afonso da. Curso de direito constitucional positivo. São Paulo: Malheiros, 2014.

SILVA, Marco Antônio Marques da. Acesso à justiça penal e estado democrático de direito. São Paulo: Juarez de Oliveira, 2001.

SILVA, Marco Antônio Marques da (coord.). Processo penal constitucional e garantias constitucionais. Rio de Janeiro: Quartier Latin, 2006.

SILVA, Marco Antônio Marques da. Miranda, Jorge (coord.). Tratado Luso-Brasileiro da Dignidade Humana. 2. ed. Lisboa;São Paulo: Almedina/Quartier Latin, 2009. 